\title{
EDUCAÇÃO E TRABALHO uma relação tão necessária quanto insuficiente
}

\author{
Liliana Rolfsen Petrilli Segnini \\ Professora do Departamento de Ciências Sociais Aplicadas à Educação da Faculdade de Educação na Universidade Estadual de Campinas. \\ Autora do livro Mulheres no Trabalho Bancário. Difusão Tecnológica, Qualificação e Relações de Gênero, entre outros.
}

\begin{abstract}
Resumo: Este artigo estabelece relação entre educação, trabalho e desenvolvimento. Para tanto, são construídos argumentos na contra-corrente dos discursos e políticas observadas neste momento, formulados com freqüência pelos organismos internacionais reguladores, pelo Estado e outras instituições.

Palavras-chave: educação e trabalho; educação no Brasil; mercado de trabalho.
\end{abstract}

Cabe acrescentar que, mesmo independentemente desse ideal de cultura, a simples alfabetização em massa não constitui talvez um benefício sem par. Desacompanhada de outros elementos fundamentais da educação, que a completem, é comparável, em certos casos, a uma arma de fogo posta na mão de um cego.

Holanda, 1995:166

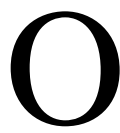
objetivo deste trabalho é indagar se a relação direta, com ou sem pálidas mediações, que tem sido estabelecida entre educação, trabalho e desenvolvimento, tão apregoada nos últimos tempos, não se constitui muito mais de um processo social de legitimação das mudanças no mercado de trabalho, via desemprego e precariedade social, do que uma real e concreta exigência dos processos de produção de bens e serviços. Num país de 157 milhões de habitantes, onde a taxa de analfabetismo atinge $20,1 \%$ da população de 15 anos ou mais (Fundação IBGE, Informe estatístico de 1996), é necessário ter cautela e restringir a argumentação para ela não correr o risco de ser irresponsável ou interpretada de forma equivocada.

Nesse sentido, é bom salientar que este trabalho não se refere à educação compreendida como um fim em si mesma, educação-processo, que nos permite tomar consciência de nós mesmos, de nossa trajetória histórica enquanto indivíduos, nação ou mundo; das contradições e desigualdades presentes na sociedade em que vivemos; de nossas especificidades culturais (sobretudo através do conhecimento do outro); das profundas desigualdades sociais existentes, concentração da terra e da renda, altas taxas de analfabetismo ao lado de violência e não-direito à saúde, ausência de valores éticos que sustentam a solidariedade. Educação que não estabelece relação direta com o mundo do trabalho. É muito mais ampla, possibilitando o desenvolvimento de políticas e ações concretas que rompam definitivamente o quadro social e econômico apontado. Não é esse o resultado da relação educação, trabalho e desenvolvimento que este trabalho analisa.

Seu objetivo, portanto, é chamar a atenção para a relação educação, trabalho e desenvolvimento, percorrendo caminhos na contra-corrente dos discursos e políticas observados neste momento, formulados com frequiência pelos organismos internacionais reguladores (Banco Mundial, FMI, e outros), pelo Estado, instituições representantes de interesses patronais, instituições representantes dos interesses dos trabalhadores, empresas, imprensa e um grande número de pesquisas científicas. Parece haver uma névoa que encobre essa relação, ou melhor, não é possível enxergá-la bem porque é portadora de excesso de luminosidade e formava um dos elementos que constroem o consenso, no interior de conflitos e interesses antagônicos. Ou, como afirma Tanguy, essa relação aparece como uma "ideologia conservadora de nosso tem- 
po" no sentido analisado por Karl Mannhein, ou seja, assegura coesão social, legitima e dissimula a ordem social existente (Tanguy, 1998).

\section{CONTEXTO SOCIAL E ECONÔMICO DA RELAÇÃO EDUCAÇÃO, TRABALHO E DESENVOLVIMENTO}

Observando a dinâmica dos mercados quer seja de bens e serviços, financeiros ou de trabalho, apreende-se que algo significativo se alterou nos últimos 30 anos nas sociedades capitalistas que se reorganizam e se reestruturam no sentido de introduzir novas formas de racionalização do trabalho e da vida social. Esse parece ser o único ponto comum no intenso debate que acompanha o esforço para compreender o processo observado há 30 anos, mas ainda em curso (Arrighi, 1997; Harvey, 1992:176); mesmo que, para alguns, essas mudanças signifiquem tão-somente a intensificação de um processo observado desde os primórdios do próprio capitalismo, questionando os aspectos ideológicos das novas formas de racionalização aplicadas (Pollert, 1988; Gordon, 1988 e Sayer, 1989 apud Harvey, 1992).

Compreende-se que esse processo revela características e contradições específicas, da mesma forma que, em outros momentos históricos, outras tantas foram observadas. Portanto, não se fala de "impactos" mas de processos expressos, neste atual contexto, pela globalização dos mercados de bens e fluxos financeiros e o acirramento da concorrência; difusão do ideário neoliberal que, contraditoriamente, requer políticas estatais que garantam a desregulamentação de normas de concorrência e direitos sociais. Nesse sentido, a concentração de capital - fusões, incorporações, privatizações - ocorre ao mesmo tempo que a força de trabalho fragiliza-se pela flexibilização, quer seja das estruturas produtivas, das formas de organização do trabalho, da própria força de trabalho, por meio do emprego/desemprego. É dentro dessa nova correlação de forças que se concretiza a lógica do "livre mercado", sob a coordenação do sistema financeiro global.

Difundem-se, cada vez mais intensamente, tecnologias produtivas apoiadas na microeletrônica como a automação, a informática, a telemática. A opção política do uso dessas tecnologias tem sido direcionada para intensificar a produtividade e a supressão do emprego.

A estrutura do mercado de trabalho também tem passado por mudanças: altas taxas de desemprego são acompanhadas da crescente insegurança e precariedade das novas formas de ocupação. A flexibilização da força de trabalho (contratos de tempo parcial, subcontratação, terceirização, etc.) inscreve-se no mesmo processo que articula o discurso por maiores níveis de escolaridade para os trabalhadores que permanecem empregados e ocupam postos de trabalho considerados essenciais para os processos produtivos nos quais se inserem.

Nesse sentido, a educação e a formação profissional aparecem hoje como questões centrais pois a elas são conferidas funções essencialmente instrumentais, ou seja, capazes de possibilitar a competitividade e intensificar a concorrência, adaptar trabalhadores às mudanças técnicas e minimizar os efeitos do desemprego. O papel de organismos internacionais reguladores tem sido fundamental para tanto, como é possível apreender a partir de prescrições do Banco Mundial: "Detalhados estudos econométricos indicam que as taxas de investimentos e os graus iniciais de instrução constituem robustos fatores de previsão de crescimento futuro. Se nada mais mudar, quanto mais instruídos forem os trabalhadores de um país, maiores serão suas possibilidades de absorver as tecnologias predominantes, e assim chegar a um crescimento rápido da produção. (...) $\mathrm{O}$ desenvolvimento econômico oferece aos participantes do mercado de trabalho oportunidades novas e em rápida mudança" (Banco Mundial, 1995:26-35).

Essas tendências, observadas mundialmente, expressam-se de forma heterogênea em diferentes contextos nacionais; no Brasil, mesclam-se com problemas sociais jamais resolvidos como a profunda desigualdade da distribuição da renda, o analfabetismo e os baixos índices de escolaridade que atingem grande parte da população, a saúde, tudo com implicações perversas nas parcas condições para o exercício da cidadania.

\section{ESPECIFICIDADES DA REESTRUTURAÇÃO NO MERCADO DE TRABALHO}

É possível observar, após terem decorrido quase três décadas de mudanças nas formas de racionalização do capitalismo, que o desenvolvimento econômico não mais significa desenvolvimento social, como ocorreu em países hoje considerados desenvolvidos por um longo período (Castel, 1998). O desemprego já não é resultado da ausência de crescimento econômico, mas se tornou inerente ao próprio crescimento econômico. No Brasil, essa relação nunca havia se dado de forma intensiva; talvez a melhor expressão do avanço do capi- 
talismo no Brasil seja justamente o registro de profunda heterogeneidade produtiva e desigualdade das relações de trabalho.

O mercado de trabalho brasileiro não conseguiu estabelecer uma situação em que o emprego formal (aquele que possibilita garantias e direitos sociais) tenha se tornado algo generalizado para o conjunto da população; ao contrário, criou-se um mercado "altamente flexível" com situações completamente diferenciadas e, em grande medida, precárias.

No entanto, como bem salienta Pochmann, ao se tomar como medida o período 1940-1980, é possível observar um crescimento das relações formais de trabalho no Brasil, que ocorreu, sobretudo, por força da introdução do projeto de industrialização nacional (de forma intensa entre 1950 e 1980), bem como devido à institucionalização das relações de trabalho por meio de um conjunto de normas legais estabelecidas pela Consolidação das Leis do Trabalho (CLT), em junho de 1943. No período, o trabalho assalariado, com registro em carteira profissional, cresceu de $12,1 \%$ para $49,2 \%$, o que significa, em termos absolutos, uma variação anual de 484,2 mil trabalhadores. Isso permite observar que, de acordo com dados do IBGE, de cada dez ocupações geradas, oito eram assalariadas, sendo sete com registro e uma sem registro (Pochmann, 1998).

Apesar desses dados, sabe-se que sua homogeneização não se deu nos níveis observados nos países desenvolvidos, onde $80 \%$ da PEA urbana eram assalariados; nos quais, através de muitas lutas, o trabalho assalariado se tornou um pilar, no qual o trabalho significava bem mais que um trabalho, significava ter direitos que se expandiam e "que a vulnerabilidade e a precariedade eram acompanhadas pela certeza que amanhã será melhor" (Castel, 1998).

No Brasil, a PEA urbana de ocupados assalariados passou de $42 \%$, em 1940, para 62,8\%, em 1980. Nesse contexto, é importante salientar, a sociedade permaneceu desigual, a renda continuou sendo concentrada e permaneceram os problemas de informalidade, subemprego, baixos salários e desigualdades de rendimentos (Pochmann, 1998). Em 1983, os $50 \%$ mais pobres da população se apropriavam de apenas $13,6 \%$ da renda total do país, enquanto os $10 \%$ mais ricos detinham $46,2 \%$.

No período analisado, o salário mínimo foi perdendo poder de compra ao mesmo tempo que elevados índices de crescimento econômico eram registrados pelo Produto Interno Bruto; ao mesmo tempo, cada vez mais horas de trabalho eram necessárias para a compra da ração essencial. O país se urbanizou e algumas conquistas sociais foram observadas, como o crescimento da esperança média de vida, que passou de 45,9 anos em 1950 para $60 \mathrm{em}$ 1980, indicando melhorias nas condições gerais de saúde e atendimento médico. Também as taxas de analfabetismo foram decrescendo constantemente, passando de $53,9 \%$ entre os homens e $60,6 \%$ entre as mulheres em 1950, para $34,9 \%$ e $35,2 \%$, respectivamente, em 1980 (Fausto, 1998).

O conjunto de medidas de ajustes macroeconômicos, a partir dos anos 80 , diante do crescimento da dívida externa e do colapso do financiamento da economia brasileira, concorreu para fortes e rápidas oscilações econômicas, estagnação e hiperinflação. Nesse contexto observa-se que a tendência à frágil estruturação do mercado de trabalho no Brasil foi rompida (Pochmann, 1998).

Sistematizando dados produzidos pelo Ministério do Trabalho (Rais e Caged) e pelo IBGE, Pochmann registra que, a partir dos anos 80, a progressiva desestruturação do mercado de trabalho foi marcada pelo desassalariamento de parcela crescente da PEA, crescimento do desemprego e do trabalho informal precário. Os postos de trabalho abertos passaram a ser sobretudo de assalariados sem registro e por conta própria.

O trabalho assalariado decresceu de $62,8 \%$ para $62,6 \%$ no período 1989-1991, sendo que esse índice de redução refere-se àqueles trabalhadores que já possuíam registro em carteira - de $49,2 \%$ para $36,6 \%$ (Tabela 1). O trabalho assalariado sem registro cresceu de $13,6 \%$ para $25,7 \%$. No período 1989-1995, o mesmo movimento continua a ser observado, intensificando-se: o trabalho assalariado decresceu de $62,8 \%$ para $58,2 \%$, enquanto o trabalho com registro passou de $49,2 \%$ para $30,9 \%$; o trabalho assalariado sem registro voltou a crescer de $13,6 \%$ para $27,3 \%$ (Pochmann, 1998).

TABELA 1

Trabalho Assalariado com e sem Registro em Carteira Brasil - 1989-1995

\begin{tabular}{lccc} 
& & \multicolumn{2}{c}{ Em porcentagem } \\
\hline Trabalho Assalariado & 1989 & 1991 & 1995 \\
\hline Total & $\mathbf{6 2 , 8}$ & $\mathbf{6 2 , 6}$ & $\mathbf{5 8 , 2}$ \\
Com Registro & 49,2 & 36,6 & 30,9 \\
Sem Registro & 13,6 & 25,7 & 27,3 \\
\hline
\end{tabular}

Fonte: Ministério do Trabalho (Rais e Caged); Fundação IBGE/PNADs ajustadas (Pochmann, 1998). 
Mesmo nos períodos de recuperação econômica (198486 e 1993-95), o desemprego e a precariedade no trabalho continuaram a crescer. Assim, a expansão das ocupações no período 1989-1996 foi de 11,4\%, enquanto a PEA total aumentou $16,5 \%$, influenciando no crescimento do desemprego em 179,1\% (Tabela 2).

Pochmann relaciona essas tendências ao abandono do projeto de industrialização nacional, à implementação do programa neoliberal oriundo do Consenso de Washington, às políticas macroeconômicas de inserção do país (que permanece subordinado) no processo de globalização; porém, acompanhadas de uma abertura comercial indiscriminada, ausência de políticas setoriais defensivas, sobrevalorização da moeda e elevados juros. Nesse contexto, o processo de reestruturação produtiva no Brasil é introduzido, resguardando a característica do próprio mercado brasileiro, ou seja, a heterogeneidade produtiva e a desigualdade no mercado de trabalho.

\section{TABELA 2}

População Economicamente Ativa (PEA), Ocupada e Desempregada Brasil - 1989-1996

\begin{tabular}{|c|c|c|c|c|c|}
\hline \multirow{3}{*}{ PEA } & \multicolumn{2}{|c|}{1989} & \multicolumn{2}{|c|}{1996} & \multirow{3}{*}{ Variação } \\
\hline & №s & & №s & & \\
\hline & Abs. & $\%$ & Abs. & $\%$ & \\
\hline Total & 60.120 & 100,0 & 70.040 & 100,0 & 16,5 \\
\hline Ocupada & 58.300 & 97,0 & 64.960 & 92,7 & 11,4 \\
\hline Desempregada & 1.820 & 3,0 & 5.080 & 7,3 & 179,1 \\
\hline
\end{tabular}

Fonte: Fundação IBGE/PNADs ajustadas (Pochmann, 1998:6).

\section{TRABALHO E ESCOLARIDADE}

Várias contradições foram observadas e serão tomadas aqui como argumentos para questionar o consenso que a relação entre trabalho e educação parece ser portadora. Em primeiro lugar, aponta-se o crescente desemprego de trabalhadores escolarizados, mesmo em um contexto como o brasileiro, no qual a educação ainda não é um direito conquistado por todos; e, em seguida, questiona-se essa relação a partir das desigualdades geracionais, raciais e de gênero.

O desemprego crescente de trabalhadores escolarizados, sobretudo nos setores mais modernos da sociedade, é tomado como um dos argumentos para tornar relativa essa perspectiva instrumental da educação que se expressa como se fosse capaz de garantir o emprego ou, até mesmo, o trabalho.
Nesse sentido, os dados sistematizados pelos economistas Marcelo Ikeda, do Programa das Nações Unidas para o Desenvolvimento Econômico (PNUD) e Sheila Najberg, do Banco Nacional de Desenvolvimento Econômico e Social (BNDES), a partir dos dados do Cadastro Geral de Empregados e Desempregados (Caged), do Ministério do Trabalho, informam que no ano de 1996 os trabalhadores da indústria com ensino superior completo foram desempregados $(6,1 \%)$ mais intensamente que os analfabetos $(4,4 \%)$ (Tabela 3$)$. No ano seguinte, a taxa de desemprego dos trabalhadores com superior completo $(2,9 \%)$ permaneceu maior que a daqueles que não haviam completado a oitava série do ensino fundamental $(2,6 \%)$ (Tabela 4).

TABELA 3

Trabalhadores Formais da Indústria Admitidos e Desligados, segundo Grau de Instrução Brasil - 1996

\begin{tabular}{lrrrr}
\hline Grau de Instrução & Admitidos & Desligados & $\begin{array}{r}\text { Saldo } \\
\text { Líquido }\end{array}$ & $\begin{array}{c}\% \text { Sobre } \\
1995\end{array}$ \\
\hline Analfabeto & 87.118 & 94.272 & -7.155 & $-4,4$ \\
4a Série Incompleta & 297.277 & 328.327 & -31.050 & $-5,2$ \\
4a Série Completa & 457.146 & 527.440 & -70.298 & $-6,8$ \\
8a Série Incompleta & 626.331 & 651.293 & -24.962 & $-2,0$ \\
8a Série Completa & 456.858 & 462.903 & -6.044 & $-0,7$ \\
2o- Grau Incompleto & 213.984 & 205.753 & 8.231 & 1,8 \\
2o- Grau Completo & 257.327 & 245.727 & 11.601 & 1,8 \\
Superior Incompleto & 45.800 & 49.832 & -4.032 & $-2,7$ \\
Superior Completo & 68.665 & 83.582 & -14.916 & $-6,1$ \\
Ignorado & 19.494 & 15.868 & 3.626 & 11,1 \\
\hline
\end{tabular}

Fonte: Ministério do Trabalho - MTb/Caged. Elaboração Marcelo Ikeda e Sheila Najberg.

TABELA 4

Trabalhadores Formais da Indústria Admitidos e Desligados, segundo Grau de Instrução Brasil - 1997

\begin{tabular}{lrrrc}
\hline Grau de Instrução & Admitidos & Desligados & $\begin{array}{r}\text { Saldo } \\
\text { Líquido }\end{array}$ & $\begin{array}{c}\text { \% Sobre } \\
1996\end{array}$ \\
\hline Analfabeto & 82.344 & 97.555 & -15.211 & $-9,8$ \\
4a Série Incompleta & 251.374 & 304.837 & -53.462 & $-9,5$ \\
4a Série Completa & 405.370 & 478.126 & -72.755 & $-7,5$ \\
8a Série Incompleta & 609.746 & 640.951 & -31.204 & $-2,6$ \\
8a Série Completa & 485.650 & 467.778 & 17.872 & 2,0 \\
2o Grau Incompleto & 233.725 & 218.677 & 15.047 & 3,2 \\
2o Grau Completo & 300.709 & 273.780 & 26.929 & 4,1 \\
Superior Incompleto & 50.526 & 51.322 & -796 & $-0,6$ \\
Superior Completo & 87.146 & 93.719 & -6.573 & $-2,9$ \\
Ignorado & 14.409 & 11.256 & 3.153 & 8,7 \\
\hline
\end{tabular}

Fonte: Ministério do Trabalho - MTb/Caged. Elaboração Marcelo Ikeda e Sheila Najberg. 
O desemprego de trabalhadores, em decorrência do processo de reestruturação, acrescenta uma nova dimensão aos problemas sociais que marcam há muito o Brasil, até então, miséria, pobreza, não-acesso à educação e à saúde. Trata-se do desemprego de trabalhadores escolarizados como, por exemplo, ocorreu intensamente na última década com os bancários no país, categoria que vivenciou o desemprego de $600 \mathrm{mil}$ trabalhadores (Segnini, 1999).

As pesquisas recentes sobre reestruturação em vários setores estão apontando para a intensificação do trabalho e não para conteúdos mais sofisticados e elaborados das atividades ou, para maior autonomia dos trabalhadores, que justificariam efetivamente maior escolaridade e qualificação (Rizek e Leite, 1998; Segnini, 1998). O número reduzido de trabalhadores atingidos por essas mudanças, com alguma positividade expressa pela democracia industrial, está inserido no chamado setor de ponta, essencialmente nos segmentos nobres das empresas multinacionais de acordo com dados da Organização Internacional do Trabalho, em 1996. São 73 milhões de pessoas, das quais 12 milhões no Terceiro Mundo; sendo que a PEA do Terceiro Mundo é da ordem de 2,2 bilhões de pessoas (Dowbor, 1998).

No mesmo processo, mas de outro lado, estão 800 milhões de desempregados no mundo (OCDE apud Dowbor, 1998), sendo 18,1 milhões na União Européia (Eurostat apud Dowbor, 1998), como resultado de um crescimento econômico perverso, que cada vez mais concentra renda (fusões, incorporações, privatizações) aprofundando o fosso entre dois pólos. Em um contexto de produtividade crescente, o Brasil insere-se nessa perspectiva de desenvolvimento, triplicando o número de desempregados no período 1989-97, chegando a 5,1 milhões de pessoas, o que equivale a 7,3\% da PEA (Fundação IBGE, 1997). Em 1995, $28,7 \%$ da população brasileira vivia com menos de um salário mínimo (Banco Mundial, 1997:224) (Tabela 5).

Os jovens no Brasil, assim como em outros países do mundo, constituem o grupo social mais escolarizado e mais desempregado, ou, mesmo, inserido em trabalhos precários. Por exemplo, para os mais escolarizados, observase a proliferação do subemprego com a denominação estágio (Tanguy, 1998). Em São Paulo, de acordo com o Seade/Dieese, 800 mil jovens entre 15 e 24 anos estão sem ocupação, representando metade dos desempregados da Região Metropolitana de São Paulo, estimada em 1,6 milhão. ${ }^{1}$
Também deve ser apontada a desigualdade entre homens e mulheres, brancos e negros com o mesmo tempo de escolaridade, no mercado de trabalho, tanto em rendimentos como em condições de trabalho. A Pesquisa de Padrão de Vida (IBGE) divulgada em agosto de 1998, realizada em 5 mil domicílios nas regiões Sudeste e Nordeste, de março de 1996 a março de 1997, registra a desigualdade salarial entre trabalhadores chefes de família com 12 anos ou mais de estudo (Tabela 6).

TABELA 5

Taxas de Desemprego e Produto Interno Bruto Brasil e Região Metropolitana de São Paulo - 1983-97

\begin{tabular}{lccccc}
\hline & \multicolumn{3}{c}{ Taxas de Desemprego (\%) } & \\
\cline { 2 - 4 } Anos & IBGE & \multicolumn{2}{c}{ Seade-Dieese (RMSP) } & PIB Real \\
\cline { 3 - 4 } & (Índice) \\
\cline { 3 - 4 } & (Brasil) & Aberto & Oculto & Total & \\
\hline 1983 & 6,7 & - & - & & 100,0 \\
1984 & 7,1 & & & & 105,3 \\
1985 & 5,2 & 7,6 & 4,6 & 12,2 & 113,6 \\
1986 & 3,6 & 6,0 & 3,6 & 9,6 & 122,2 \\
1987 & 3,7 & 6,3 & 2,9 & 9,2 & 126,6 \\
1988 & 3,8 & 7,0 & 2,7 & 9,7 & 126,4 \\
1989 & 3,3 & 6,5 & 2,2 & 8,7 & 130,6 \\
1990 & 4,9 & 7,4 & 2,9 & 10,3 & 124,9 \\
1991 & 6,0 & 7,9 & 3,8 & 11,7 & 125,3 \\
1992 & 7,1 & 9,2 & 6,0 & 15,2 & 124,3 \\
1993 & 6,1 & 8,6 & 6,0 & 14,6 & 129,5 \\
1994 & 5,8 & 8,9 & 5,3 & 14,2 & 137,1 \\
1995 & 5,5 & 9,0 & 4,2 & 13,2 & 143,2 \\
1996 & 6,7 & 10,0 & 5,1 & 15,1 & 148,3 \\
1997 & 7,3 & 10,3 & 5,7 & 16,0 & 152,4 \\
& & & & & \\
\hline
\end{tabular}

Fonte: Fundação IBGE. Pesquisa Mensal de Emprego; SEP. Convênio Seade-Dieese. Pesquisa de Emprego e Desemprego - PED.

TABELA 6

Rendimento Médio Mensal dos Trabalhadores Chefes de Família com 12 Anos ou Mais de Estudo, segundo Sexo e Cor Regiões Sudeste e Sudoeste - 1997

Em reais

\begin{tabular}{lc}
\hline Sexo e Cor & Rendimento Médio Mensal \\
\hline Branco & \\
Homem & 881,00 \\
Mulher & 559,00 \\
& \\
Negro & \\
Homem & 423,00 \\
Mulher & 266,00 \\
\hline
\end{tabular}

Fonte: Fundação IBGE. Pesquisa de Padrão de Vida, 1998. 
A qualificação (escolaridade e formação profissional) se transformou no fetiche capaz de romper esse processo. Somas vultosas estão sendo gastas no mundo inteiro para requalificar trabalhadores. Os resultados são pífios se mensurados a partir da reinserção no mercado de trabalho, como atestam pesquisas em vários países. Também no Brasil, através do Programa Nacional de Qualificação do Trabalhador (Planfor), com verbas do Fundo do Amparo ao Trabalhador (FAT), constituído pelas contribuições do PIS e Pasep, foram despendidos 596,3 milhões de reais (45\% na região Sudeste do país) para atender a 3,3 milhões de trabalhadores. Em São Paulo, de acordo com dados da Secretaria do Trabalho, $11 \%$ dos trabalhadores que cursaram programas de formação conseguiram se inserir no mercado de trabalho, em 1997 (Unitrabalho, 1997).

\section{ESCOLARIDADE E DESIGUALDADE NO MERCADO DE TRABALHO: UM ENFOQUE DE GÊNERO}

Um argumento substantivo apontado para tornar relativa a relação entre escolaridade e inserção no mercado de trabalho é encontrado na condição desigual vivida pela mulher.

No Brasil, as mulheres também vivenciaram, nos últimos 30 anos, inegáveis ganhos sociais, políticos e econômicos observados em vários estudos referentes a outros contextos nacionais, sobretudo nos países desenvolvidos.

Nesse sentido, o crescimento da participação das mulheres no mercado de trabalho, após a década de 60 até 1995, é um dos indicadores mais elucidativos para acompanhar este processo em decorrência do significado social que expressa (Tabela 7).

No período enfocado (1985-1995), o crescimento da participação da mulher no mercado de trabalho $(63,0 \%)$ é significativamente superior ao do homem (20,8\%). Isso quer dizer que a porcentagem de mulheres na PEA elevou-se de
36,9\%, em 1985, para 53,4\%, em 1995; no mesmo período, a taxa de atividade masculina registrou discreto crescimento de $76,0 \%$ para $78,3 \%$. Dessa forma, em 1995 , a proporção de mulheres entre os trabalhadores era de 40,4 \% (1985 $=33,5 \%$ ), enquanto para os homens foi registrado um decréscimo de 66,5\%, em 1985, para 59,6\%, em 1995.

Considerando a distribuição da PEA masculina e feminina por escolaridade, observou-se que os índices de escolaridade das mulheres, a partir do 8 o ano de estudo, superam a escolaridade masculina (Tabela 8).

No entanto, a análise dos dados apontados não permitem a afirmação que esse crescimento refere-se tão-somente a uma conquista social das mulheres na busca de oportunidades iguais às dos homens. Em alguns aspectos, para algumas mulheres, uma minoria, sim; mas não apenas.

A segregação sexual no trabalho persiste como um fenômeno mundial. O inegável crescimento da participação das mulheres no mercado de trabalho e a escolaridade elevada alteram pouco suas condições socioeconômicas. A desigualdade entre homens e mulheres se expressa de diferentes formas, como a posição ocupada pelas mulheres no mercado de trabalho $(17,2 \%$ de trabalhadoras domésticas, $13,1 \%$ de não-remuneradas, $9,3 \%$ de trabalhadoras para auto-consumo), perfazendo um percentual de $40 \%$ de postos de trabalho precários enquanto para os homens esse índice é de 10,7\%. Mesmo entre as mulheres empregadas $(41,9 \%)$ é possível observar que vários indicadores (rendimento, jornada de trabalho, registro em carteira e direitos no trabalho) apontam para a precária condição da maioria das mulheres na ocupação de postos de trabalho que demandam menor qualificação reconhecida efetivamente pela remuneração, como no setor de prestação de serviços onde trabalham 29,8\% das mulheres e $12 \%$ dos homens. Entre esses(as) trabalhadores(as), 78\% das mulheres e $43 \%$ dos homens incluem-se na classe de rendimento mensal de até $\mathrm{R} \$ 240,00$ (Bruschini, 1998). O movimento das desigualda-

TABELA 7

Indicadores de Participação Econômica, segundo Sexo Brasil - 1985-1995

\begin{tabular}{|c|c|c|c|c|c|c|c|c|c|c|}
\hline \multirow[t]{2}{*}{ Sexo } & \multicolumn{3}{|c|}{ PEA (Em milhões) } & \multirow{2}{*}{$\begin{array}{c}\text { Variação } \\
1985 / 95 \\
(\%)\end{array}$} & \multicolumn{3}{|c|}{ Taxa de Atividade (\%) } & \multicolumn{3}{|c|}{$\begin{array}{c}\text { Proporção de Mulheres entre } \\
\text { os Trabalhadores (\%) }\end{array}$} \\
\hline & 1985 & 1990 & 1995 & & 1985 & 1990 & 1995 & 1985 & 1990 & 1995 \\
\hline Homem & 36,6 & 41,6 & 44,2 & 20,8 & 76,0 & 75,3 & 78,3 & 66,5 & 64,5 & 59,6 \\
\hline Mulher & 18,4 & 22,9 & 30,0 & 63,0 & 36,9 & 39,2 & 53,4 & 33,5 & 35,5 & 40,4 \\
\hline
\end{tabular}

Fonte: Fundação IBGE, Pesquisa Nacional por Amostra de Domicílios - PNAD 1985, 1990 e 1995 (Bruschini, 1998). 
des é registrado tanto pelo IBGE como pelo Seade/Dieese, mesmo com a utilização de metodologias diferenciadas para suas coletas de dados e números diferentes entre si.

TABELA 8

População Economicamente Ativa, por Sexo, segundo Anos de Estudo Brasil - 1993-1995

\begin{tabular}{|c|c|c|c|c|}
\hline \multirow{2}{*}{ Anos de Estudo } & \multicolumn{2}{|c|}{1993} & \multicolumn{2}{|c|}{1995} \\
\hline & Homens & Mulheres & Homens & Mulheres \\
\hline Total (Em milhões) & 42,9 & 28,0 & 44,2 & 30,0 \\
\hline Total $(\%)$ & 100,0 & 100,0 & 100,0 & 100,0 \\
\hline \multicolumn{5}{|l|}{ Sem Instrução e } \\
\hline Menos de 1 Ano & 17,0 & 14,4 & 16,3 & 13,2 \\
\hline 1 a 3 Anos & 20,0 & 17,4 & 19,0 & 16,5 \\
\hline 4 a 7 Anos & 34,1 & 32,0 & 34,1 & 31,9 \\
\hline 8 a 10 Anos & 12,7 & 13,0 & 13,4 & 13,6 \\
\hline 11 a 14 Anos & 11,6 & 16,9 & 12,2 & 18,1 \\
\hline 15 Anos ou Mais & 4,5 & 6,0 & 4,8 & 6,5 \\
\hline
\end{tabular}

Fonte: Fundação IBGE. Pesquisa Nacional por Amostra de Domicílios - PNAD 1993 e 1995 (Bruschini, 1998).

TABELA 9

Distribuição dos Ocupados, por Sexo, segundo Posição na Ocupação e Classes de Rendimento Mensal no Trabalho Principal

Brasil - 1993-1995

\begin{tabular}{|c|c|c|c|c|}
\hline \multirow{2}{*}{$\begin{array}{l}\text { Posição na Ocupação e } \\
\text { Classes de Rendimento } \\
\text { Mensal do Trabalho Principal }\end{array}$} & \multicolumn{2}{|c|}{1993} & \multicolumn{2}{|c|}{1995} \\
\hline & Homens & Mulheres & Homens & Mulheres \\
\hline Empregados (Em milhões) & 23,7 & 11,1 & 23,8 & 11,5 \\
\hline$(\mathrm{Em} \%)$ & 100,0 & 100,0 & 100,0 & 100,0 \\
\hline Até 2 Salários Mínimos & 56,5 & 62,8 & 45,7 & 50,5 \\
\hline Mais de 2 a 5 Salários Mínimos & 28,2 & 25,5 & 33,9 & 32,3 \\
\hline Mais de 5 Salários Mínimos & 14,6 & 11,0 & 20,5 & 17,2 \\
\hline Sem Declaração & 0,7 & 0,6 & - & - \\
\hline \multicolumn{5}{|l|}{ Trabalhadores Domésticos } \\
\hline (Em milhões) & 0,3 & 4,2 & 0,3 & 4,7 \\
\hline$(\mathrm{Em} \%)$ & 100,0 & 100,0 & 100,0 & 100,0 \\
\hline Até 2 Salários Mínimos & 89,4 & 96,6 & 79,5 & 90,4 \\
\hline Mais de 2 a 5 Salários Mínimos & 9,5 & 2,8 & 17,3 & 8,9 \\
\hline Mais de 5 Salários Mínimos & 0,3 & 0,1 & 3,2 & 0,6 \\
\hline Sem Declaração & 0,8 & 0,6 & - & - \\
\hline Conta-Própria (Em milhões) & 10,2 & 4,1 & 10,8 & 4,5 \\
\hline$(E m \%)$ & 100,0 & 100,0 & 100,0 & 100,0 \\
\hline Até 2 Salários Mínimos & 53,3 & 74,9 & 50,4 & 70,1 \\
\hline Mais de 2 a 5 Salários Mínimos & 28,9 & 15,5 & 29,6 & 19,5 \\
\hline Mais de 5 Salários Mínimos & 14,7 & 6,9 & 20,0 & 10,3 \\
\hline Sem Declaração & 3,4 & 2,8 & - & - \\
\hline Empregadores (Em milhões) & 2,0 & 0,4 & 2,1 & 0,5 \\
\hline$(E m \%)$ & 100,0 & 100,0 & 100,0 & 100,0 \\
\hline Até 2 Salários Mínimos & 13,4 & 18,9 & 9,7 & 10,5 \\
\hline Mais de 2 a 5 Salários Mínimos & 26,8 & 33,9 & 22,0 & 24,8 \\
\hline Mais de 5 Salários Mínimos & 57,6 & 43,7 & 68,4 & 64,6 \\
\hline Sem Declaração & 2,3 & 3,4 & - & - \\
\hline
\end{tabular}

TABELA 10

Rendimentos dos Ocupados, por Sexo

Brasil - 1985-1995

\begin{tabular}{lccc}
\hline & \multicolumn{2}{c}{$\begin{array}{c}\text { Rendimento dos Ocupados } \\
\text { (Em salários mínimos) }\end{array}$} & $\begin{array}{c}\text { Diferença } \\
(\%)\end{array}$ \\
\cline { 2 - 3 } Anos & Mulheres & Homens & \\
\hline 1985 & 1,9 & 3,7 & 51,0 \\
1986 & 2,7 & 5,3 & 51,0 \\
1987 & 2,1 & 4,0 & 53,0 \\
1988 & 2,1 & 4,0 & 53,0 \\
1989 & 2,5 & 4,7 & 53,0 \\
1990 & 2,2 & 3,8 & 58,0 \\
1992 & 1,7 & 3,1 & 55,0 \\
1993 & 1,8 & 3,5 & 51,0 \\
1995 & 2,4 & 4,4 & 55,0 \\
\end{tabular}

Fonte: Fundação IBGE. Pesquisa Nacional por Amostra de Domicílios - PNAD 1995 (Bruschini, 1998). Nota: Não estão incluídos os rendimentos da população da zona rural de Rondônia, Acre, Amazonas, Roraima, Pará e Amapá. Valores inflacionados pelo INPC com base em setembro de 1995 e expressos em salários mínimos de setembro de 1995.

Observa-se a intensa participação da mulher como empregada doméstica no mercado de trabalho, entre as quais $90,4 \%$ recebem até dois salários mínimos, e a irrisória participação como empregadora $(0,5 \%)$. No entanto, em qualquer ocupação, as mulheres recebem salários menores que os homens.

Dados produzidos pelo Seade/Dieese registram que o rendimento médio das mulheres em 1996 ( $\mathrm{R} \$ 585,00)$ correspondia a $60 \%$ do obtido pelos homens ( $\mathrm{R} \$ 995,00)$. $\mathrm{Se}$ o rendimento for considerado por hora trabalhada a diferença persiste, invalidando o argumento de que elas estariam, eventualmente, trabalhando uma quantidade menor de horas.

Precariedade no trabalho é um processo social que atinge homens e mulheres no atual momento do mercado de trabalho; porém, as mulheres já estavam em maior número nas ocupações precárias e continuam a vivenciar taxas maiores de informalidade e precariedade, apesar dos índices de escolaridade mais elevados.

Nesse sentido, pode-se afirmar que as mulheres foram pioneiras em ocupar postos de trabalho precários, que estavam por vir para ambos os sexos, no contexto da reestruturação produtiva. Mesmo assim, elas continuam campeãs em informalidade e precariedade e começam a ser mais atingidas pelo desemprego em vários setores. Essas questões precisam ser pesquisadas intensamente, mesmo porque possibilitam melhor compreensão dos processos de mudanças sociais a partir da reestruturação econômica, que ainda está em curso. 
TABELA 11

Taxas de Informalidade e Precariedade do Emprego Urbano, por Sexo Brasil - 1990-1993

\begin{tabular}{lcclll}
\hline \multirow{2}{*}{ Taxas } & \multicolumn{3}{c}{ Homem } & & \multicolumn{3}{c}{ Em porcentagem } \\
\cline { 2 - 3 } \cline { 6 - 7 } & 1990 & 1993 & & 1990 & 1993 \\
\hline Informalidade (1) & 39,09 & 44,63 & & 45,90 & 54,22 \\
Precariedade (2) & 10,51 & 19,70 & & 15,50 & 26,50 \\
\hline
\end{tabular}

Fonte: Atlas Regional das Desigualdades, Ipea-Dipes/IBGE, 1996. Lavinas e Barsted, 1996. (1) Proporção de trabalhadores conta-própria e empregados sem carteira sobre a população ocupada.

(2) Proporção de trabalhadores que trabalham mais de 40 horas por semana e ganham menos de um salário mínimo por mês sobre o total da população ocupada.

TABELA 12

Médias Anuais das Taxas de Desemprego, por Sexo Regiões Metropolitanas de São Paulo, Porto Alegre, Curitiba e Distrito Federal - 1985-97

\begin{tabular}{|c|c|c|c|c|}
\hline & & & & Em porcentagem \\
\hline \multirow[t]{2}{*}{ Anos } & São Paulo & $\begin{array}{l}\text { Distrito Federal } \\
\text { (1) }\end{array}$ & $\begin{array}{c}\text { Porto Alegre } \\
\text { (1) }\end{array}$ & $\begin{array}{l}\text { Curitiba } \\
\text { (2) }\end{array}$ \\
\hline & Mulher Homem & Mulher Homem & Mulher Homem & Mulher \\
\hline
\end{tabular}

$\begin{array}{rrrrrrrrr}1985 & 15,5 & 10,1 & & & & & & \\ 1986 & 12,7 & 7,6 & & & & & & \\ 1987 & 12,2 & 7,3 & & & & & & \\ 1988 & 12,1 & 8,1 & & & & & & \\ 1989 & 10,6 & 7,5 & & & & & & \\ 1990 & 12,1 & 9,1 & & & & & & \\ 1991 & 13,0 & 10,8 & & & & & & \\ 1992 & 17,1 & 13,9 & 17,8 & 13,7 & 16,4 & 12,5 & & \\ 1993 & 16,3 & 13,4 & 17,6 & 13,0 & 14,3 & 10,7 & & \\ 1994 & 16,4 & 12,7 & 17,0 & 12,6 & 13,2 & 10,0 & & \\ 1995 & 15,3 & 11,8 & 17,3 & 14,4 & 12,9 & 9,2 & 12,2 & 9,8 \\ 1996 & 17,2 & 13,5 & 19,1 & 15,0 & 14,1 & 12,4 & 14,4 & 12,1 \\ 1997(3) & 18,8 & 13,8 & 19,9 & 15,6 & 16,1 & 12,8 & 16,5 & 13,1\end{array}$

Fonte: SEP. Convênio Seade-Dieese, Ipardes, Sert/Sine-PR, FEE, FGTAS/Sine-RS e GDF (Codeplan e STB). Pesquisa de Emprego e Desemprego - PED.

(1) A pesquisa inicia-se em 1992.

(2) A pesquisa inicia-se em 1995.

(3) Dados referentes ao mês de junho.

TABELA 13

Taxas de Desemprego, segundo Sexo e Tipo de Desemprego Região Metropolitana de São Paulo - 1989-1997

Em porcentagem

\begin{tabular}{lrrr}
\hline Sexo e Tipos de Desemprego & 1989 & 1996 & 1997 \\
\hline Mulheres & 10,6 & 17,2 & 48,3 \\
Desemprego Aberto & 8,2 & 12,5 & 12,9 \\
Desemprego Oculto & 2,5 & 4,7 & 5,4 \\
Homens & 7,5 & 13,5 & 14,2 \\
Desemprego Aberto & 5,4 & 8,1 & 8,4 \\
Desemprego Oculto & 2,1 & 5,4 & 5,8
\end{tabular}

Fonte: SEP. Convênio Seade-Dieese. Pesquisa de Emprego e Desemprego - PED.
Nos últimos anos, as taxas de desemprego vêm apresentando crescimento acentuado para os trabalhadores de ambos os sexos, com elevação mais intensa para os homens. No entanto, historicamente, as taxas relativas às mulheres são mais altas, independentemente da região do país.

\section{CONSIDERAÇÕES FINAIS}

As contradições apontadas neste trabalho sobre a relação entre escolaridade e formas de inserção no mundo do trabalho (e do desemprego) possibilitam, em primeiro lugar, reafirmar que qualificação para o trabalho é uma relação social (de classe, de gênero, de etnia, geracional), muito além da escolaridade ou da formação profissional, que se estabelece nos processos produtivos, no interior de uma sociedade regida pelo valor de troca e fortemente marcada por valores culturais que possibilitam a formação de preconceitos e desigualdades. Isso quer dizer que os conhecimentos adquiridos pelo trabalhador através de diferentes processos e instituições sociais - família, escola, empresa, etc. - somados às suas habilidades, também adquiridas socialmente e acrescidas de suas características pessoais, de sua subjetividade, de sua visão de mundo, constituem um conjunto de saberes e habilidades que significa, para ele, trabalhador, valor de uso, que só se transforma em valor de troca em um determinado momento histórico se reconhecido pelo capital como sendo relevante para o processo produtivo.

O reconhecimento do grau de qualificação do trabalhador pelas empresas se dá através de sua particular inclusão em diferentes níveis hierárquicos e salariais, em diferentes formas de relações empregatícias como trabalho assalariado (com ou sem registro), trabalho terceirizado, contratos temporários, trabalho sem remuneração. A qualificação assim compreendida expressa relações de poder no interior dos processos produtivos e na sociedade; implica também o reconhecimento que escolaridade e formação profissional são condições necessárias, mas insuficientes, para o desenvolvimento social. Isso porque se sabe que somente políticas e ações concretas, que possibilitem real desenvolvimento social e econômico (distribuição de renda, reforma agrária, reforma do sistema de saúde e educacional), podem estar superando desigualdades e construindo condições sociais que redundam em cidadania. $\mathrm{E}$ só encontram sentido social no interior de um projeto de desenvolvimento econômico que possibilite direitos sociais, entre eles, o trabalho. Nesse contexto, educação tor- 
na-se fundamental como um fim em si mesma, como condição sine qua non para a cidadania crítica, tal como descrita na introdução deste trabalho; vinculá-la ao trabalho sem mediações tem sido relevante para culpar as vítimas (desempregados escolarizados) ou legitimar ações políticas que possibilitam a "ilusão de desenvolvimento" (Arrighi, 1997) sem alterar a ordem social desigual.

\section{NOTAS}

E-mail da autora: segnini@attglobal.net

1. "Mas o desemprego é apenas a manifestação mais visível de uma transformação profunda da conjuntura do emprego. A precarização do trabalho constituilhe uma outra característica, menos espetacular porém mais importante, sem dúvida. (...) Não para banalizar a gravidade do desemprego. Contudo, enfatizar essa precarização do trabalho permite compreender os processos que alimentam a vulnerabilidade social e produzem, no final do percurso, o desemprego e a desfiliação (Castel, 1998:514 e 516).

\section{REFERÊNCIAS BIBLIOGRÁFICAS}

ANTUNES, R. Adeus ao trabalho? Ensaio sobre as metamorfoses e a centralidade do mundo do trabalho. 2a ed. São Paulo, Cortez, Campinas, Editora da Universidade Estadual de Campinas, 1995.

APPAY, B. e THÉBAUD-MONY, A. Précarisation sociale, travail et santé. Paris, Iresco, 1997.

ARRIGHI,G. A ilusão do desenvolvimento. Rio Janeiro, Vozes, 1997.

BALTAR, P.E. de A.; DEDECCA, C.S. e HENRIQUE, W. Mercado de trabalho e exclusão social no Brasil. Campinas, Cesit/Unicamp, mimeo, sd.

BANCO MUNDIAL. Relatório sobre o Desenvolvimento Mundial. O trabalhador e o processo de integração mundial. Washington, 1995.

. Relatório sobre Desenvolvimento Mundial. O Estado num mundo em transformação. Washington, 1997.

BRUNO, L. (org.). Educação e trabalho no capitalismo contemporâneo. São Paulo, Atlas, 1996.

BRUSCHINI, M.C.A. Trabalho das mulheres no Brasil: continuidades e mudanças no período 1985-1995. São Paulo. Fundação Carlos Chagas, 1998, mimeo.

CASTEL, R. et alii. "Chômage: le cas français. Collection des rapports officiels. Rapport au Premier Ministre”. La Documentation Française. Paris, 1997.

. As metamorfoses da questão social. Uma crônica do salário. São Paulo, Vozes, 1998.

CHESNAIS, F. A mundialização do Capital. São Paulo, Xamã, 1996.

COMIM, A.A. e CARDOSO, A.M. Qualificação profissional e flexibilização do mercado de trabalho: duas teses e uma antítese. São Paulo, Ceru-USP, 1996, mimeo.

COMMAILLE, J. Les stratégies des femmes. Travail, famille et politiques. $\mathrm{Pa}-$ ris, Éditions la Decouverte, 1993.

DEDECCA, C.S. As políticas de qualificação e formação e seus efeitos sobre o mercado e as relações de trabalho: algumas experiências européias. Relatório de atividades. Projeto de Pesquisa: Emprego e Desenvolvimento Tecnológico. Campinas, CNPq-Dieese-Cesit, 1998, mimeo.

DEDECCA, C.S. e BRANDÃO, S.M.C. "Crise, transformações estruturais e mercado de trabalho". In: Crise brasileira - anos oitenta e governo Collor. São Paulo, CUT (Desep) e Instituto Cajamar (Inca), 1993.

DONIOL-SHAW, L.A. "L'évolution du rapport genre-qualification: question d'identité et de pouvoir". In: Cahiers du Gedisst - Groupe d'études sur la division sociale et sexuelle du travail. Paris, Institut de Recherche sur les Sociétés Contemporaines - CNRS, 1993.
DOWBOR, L.; IANNI, O. e RESENDE, E.A. (orgs.). Desafios da globalização. Rio de Janeiro, Vozes, 1998.

DUPUY-HERELLE, E. Femmes au chômage. Paris, Hommes et Perspectives, EPI, 1997.

EYRAUD, F. e ROZENBLATT, P. Les formes hiérarchiques: travail et salaires dans neuf pays industrializés. La Documentacion Française. Paris, 1994 (Collection Cahier Travail et Emploi).

FAUSTO, B. História do Brasil. São Paulo, Edusp - FDE, 1998.

FUNDAÇÃO IBGE. Pesquisa Nacional por Amostra de Domicílios - PNAD. Rio de Janeiro, 1981 e 1990. prtabl). Informe Estatístico 1996 (http://www.sidra.ibge.gov.br/cgi-bin/ Anuário Estatístico do Brasil. Rio de Janeiro, 1997.

FUNDAÇÃO SEADE. Mulher e Trabalho - Especial. São Paulo, 1997.

GORZ, A. Capitalisme, socialisme, écologie. França, Galilée, 1991.

GUAINO, H.; CASTEL, R.; FITOUSSI, J.-P. e FREYSSINET, J. "Chômage: le cas français. Rapport au Premier Ministre". La Documentacion Française. Paris, 1997.

HARVEY, D. A condição pós-moderna. Uma pesquisa sobre a origem da mudança cultural. São Paulo, Edições Loyola, 1992.

HIRATA, H.; LAUTIER, B. e SALAMA, P. "Les transformacions du travail (Amérique latine, Asie)”. Revue Tiers Monde. Paris, n.154, avril/juin 1998.

HIRATA, H.S. "Da polarização das qualificações ao modelo da competência: a evolução do debate no contexto dos novos paradigmas de organização industrial". Simpósio: Inovações tecnológicas, novos padrões de organização do trabalho e qualificação da mão-de-obra. Workshop Trabalho e Educação. São Paulo, Anped, 44a Anual da SBPC, 1992, mimeo.

Travail et division sexuelle du travail. Comparaisons Internationales du Travail Industriel. Mémoire de synthése pour l'habilitation à diriger recherches. Université de Versailles Saint-Quentien-Yvelines, 1997.

HOBSBAWN, E. A era dos extremos. São Paulo, Companhia das Letras, 1995. HOLANDA, S.B. Raízes do Brasil. 26aㅡ ed. São Paulo, Cia. das Letras, 1995.

HOLCMAN, R. "Le chômage- mecanismes économiques, conséquences sociales et humaines". La Documentacion Française. Paris, 1997.

IANNI, O. Teorias da globalização. 2ª ed. Rio de Janeiro, Civilização Brasileira, 1996.

JOBERT, A.; MARRY, C. e TANGUY, L. Éducation et travail en Grande Bretagne, Allemagne et Italie. Paris, Armand Colin, 1995.

LAVINAS, L. e BARSTED, L.L. "Mudanças na sociedade salarial, regulamentação e emprego feminino". Anais do X Encontro Nacional de Estudos Populacionais. Belo Horizonte, Abep, 1996.

LEITE, M. de P. O futuro do trabalho. Novas tecnologias e subjetividade operária. São Paulo, Scritta, 1995.

MARTINS, H. de S. e RAMALHO, J.R. (orgs.). Terceirização. Diversidade e negociação no mundo do trabalho. São Paulo, Hucitec, Cedi/Nets, 1994.

MARUANI, M. (coord.). "Égalité, équité, discrimination: hommes et femmes sur le marché du travail". Les Cahiers du Mage. Paris, CNRS et Communautés Européennes, Services des Droits de Femmes. n.2, 1997.

MATTOSO, J.E. "Crise, transformações produtivo-tecnológicas e trabalho - panorama visto do Brasil". Cadernos do Cesit. Campinas, Instituto de Economia da Unicamp, 1992 (Texto para Discussão n⿳⺈ 7).

$$
\text { . A desordem do trabalho. São Paulo, Scritta, } 1995 .
$$

NICOLE DRANCOURT, C. "Organisation du travail des femmes et flexibilité de l'emploi". Sociologie du Travail. Paris, XXXII, n.2/90.

OLIVEIRA, F. e PAOLI, M.C. Os sentidos da democracia. Políticas de dissenso e hegemonia global. São Paulo, Vozes, 1999.

OLIVEIRA, C.A.B. de e MATTOSO, J.E.L. (orgs.). Crise e trabalho no Brasil. Modernidade ou volta ao passado. São Paulo, Scritta, 1996.

ORGANISATION DES NATIONS UNIES. Valoriser le travail des femmes. New York, 1991.

POCHMANN, M. O movimento de desestruturação do mercado de trabalho brasileiro nos anos 90: uma análise regional. Campinas, Cesit/IE/Unicamp, 1998, mimeo. 
RIZEK, C.S. "Interrogações a um campo teórico em crise". Tempo Social. Revista de Sociologia da USP. São Paulo, v.6, n.1-2, 1994, p.147-179.

RIZEK, C. S. e LEITE, M. de P. "Dimensões e Representações do Trabalho Fabril Feminino." In: ABRAMO, L. e ABREU, A. de P. (orgs.) Gênero e Trabalho na Sociologia Latino-Americana. São Paulo; Rio de Janeiro, Alast, 1998.

ROGERAT, C. Chômage et égalité des chances. "La division sexuelle du travail revisitée”. Les Cahiers du MAGE-Marché du Travail et Genre, n.3, abril 1995.

ROLLE, P. O que é qualificação do trabalho. São Paulo, 1987, mimeo.

ROPÉ, F. e TANGUY, L. Saberes e competências. O uso de tais noções na escola e na empresa. Campinas, Papirus, 1997.

SALAMA, P. "Pauvretés au Brésil: de l'inflacion au chômage”. Problèmes d'Amérique latine. La Documentacion Française. Paris, n.21, avril/juin 1996.

SEAGER, J. Atlas. Des Femmes dans le Monde. Émancipation ou opression: un paysage contrasté. Paris, Éditions Autrement, 1997 (Collection Atlas/Monde).

SEGNINI, L.R.P. A liturgia do poder - trabalho e disciplina. São Paulo, Educ, 1988.
Mulheres no trabalho bancário: difusão tecnológica, qualificação e relações de gênero. São Paulo, Edusp, 1998.

. "Reestruturação nos bancos no Brasil: desemprego, terceirização e intensificação no trabalho". Educação e Sociedade, ano XX, n.67, ago. 1999.

Constantes recomeços: homens e mulheres em situação de desemprego. São Paulo, Fundação Carlos Chagas, 2000 (no prelo).

SINGER, P. "Desemprego e exclusão social". São Paulo em Perspectiva. São Paulo, Fundação Seade, v.10, n.1, jan.-mar. 1996.

. Globalização e desemprego - diagnóstico e alternativas. São Paulo, Contexto, 1998.

TANGUY, L. Éducation et travail en Grande Bretagne, Allemagne et Italie. Paris, Ed. Armand Colin, 1995.

. "Construction de la categorie formation dans un contexte de chômage en Grande-Bretagne". Revue Sociologie du Travail. Paris, Dunod, n.4, 1998 .

UNITRABALHO. Avaliação Nacional do Planfor - 1997. São Paulo, 1997. 